\title{
Ni capitalista, ni comunista: apuntes sobre las bases ideológicas del Gobierno Revolucionario de la Fuerza Armada del Perú (1968-1975)
}

\author{
Neither capitalists, nor communists: notes about the ideological \\ bases of the Revolutionary Government of the Peruvian armed \\ force (1968-1975)
}

\author{
${ }^{1}$ Poll Gallegos Heredia
}

\section{RESUMEN}

El Gobierno Revolucionario de la Fuerza Armada (1968-1980) es considerado un caso singular entre los regímenes militares en Latinoamérica por el profundo programa de reformas y su intento por conceptualizar una experiencia diferente a los modelos imperantes. La fijación por encaminarse hacia una tercera vía, los llevó a acercarse al humanismo cristiano y hacia una participación de corte socialista, rechazándose la verticalidad de un partido o doctrina a la cual seguir. Se impulsó la autogestión y la participación como una forma directa de intervención de la población en las reformas realizadas por los militares. Dentro de lo expuesto, proponemos acercarnos y rastrear parte de las influencias conceptuales presentes en las bases ideológicas del Gobierno de la Fuerza Armada. Con ello, trabajaremos la idea defendida de una "democracia social de participación plena" que justifica, a su vez, la insistencia en crear una experiencia original realizada en el Perú. Dichas ideas fueron sostenidas por militares e intelectuales participantes del llamado "proceso peruano".

Palabras clave: Democracia social de participación plena, Gobierno de la Fuerza Armada, Humanismo cristiano.

\section{ABSTRACT}

The Revolutionary Government of the Peruvian Armed Force (1968-1980) is considered a singular case between the military regimes in Latin America due to the profound reform program and its attempt to conceptualize a different experience from the prevailing models in that time. The determination to routed towards a third way, led them to approach a Christian humanism and a socialist participation. By rejecting the verticality of a party or doctrine to follow, self-management and participation was encourage as a direct form of intervention by the population in the reforms promoted by the military. Within the expose, we propose to approach to track part of the conceptual influences present in the ideological bases of the Government of the Armed Forces, and with this, we will work on the defended idea of a "social democracy of full participation" that justifies the insistence to create an original experience made in Peru. Military and intellectual participants of the so-called "Peruvian process" supported these ideas.

Keywords: Social democracy of full participation, Armed Forces Government, Christian Humanism.

${ }^{1}$ Instituto Raúl Porras Barrenechea. Universidad Nacional Mayor de San Marcos. Lima-Perú. E-mail: pollgallegos89@gmail.com 


\section{INTRODUCCIÓN}

Durante gran parte de la vida republicana del Perú, el Ejército había cumplido una labor intervencionista. Primero en el siglo XIX junto a los caudillos militares y posteriormente, en el siglo XX, como defensores del orden oligárquico. La modernización de la Fuerza Armada, después del desastre de 1879, se convirtió en una prioridad del Segundo Gobierno de Piérola, quien invitó a una misión francesa para mejorar la instrucción de los cadetes y oficiales que el nuevo ejército debía tener, así la institucionalización ampliaba su participación en los destinos del país.

Los sucesivos golpes de estado dirigidos por militares con apoyo del ejército, (los casos de Benavides en 1914, Sánchez Cerro en 1930 y Odría en 1948) interrumpieron el orden constitucional de gobiernos de corte populista o con acercamiento a los sectores sociales. Es a partir del gobierno del general Manuel Odría que el ejército toma otro rumbo debido a los cambios procesados en su interior con el surgimiento de la Escuela de Inteligencia del Ejército (EIE) y el Centro de Altos Estudios Militares (CAEM). Kruijt (1991) resaltó el rol de estos organismos militares, en especial del Servicio de Inteligencia que, después del cambio de dirección en el CAEM, "se convirtió en el centro de la formación de algunos de los militares progresistas"

La percepción de los nuevos cambios en los objetivos y la función del Ejército fue asimilada por los futuros generales participantes del golpe de 1968. Entre ellos, al general Jorge Fernández Maldonado; quien entendió, desde una formación estrictamente castrense, el nuevo rol que debían tener las fuerzas armadas y que "de la exclusiva preparación para la guerra se pasa a una visión diferente, más amplia, más próxima a los problemas de la realidad nacional y a sus posibles soluciones" (Del Pilar Tello, 1983).

Aquellos cambios hicieron conocer de cerca la realidad del país y motivaron a generar conclusiones personales sobre la situación social imperante, como las meditadas por el general Aníbal Meza Cuadra que presenció también muchas de las desigualdades junto a sus compañeros y concluyó que "en el Perú impera un régimen social, político y económico desesperante e inhumano para la mayoría, donde solamente la parte privilegiada era la que tenía derecho a todo" (Del Pilar Tello, 1983, p. 316).

El CAEM, dirigido por el general José del Carmen Marín en los años 50, reinterpretó la llamada "tesis de seguridad interior" por un modelo que se vinculaba más a la realidad nacional, y así los militares empezaron hablar del "binomio pueblo-fuerza armada", donde "la seguridad militar, era también seguridad económica y social" (Kruijt, 1991).

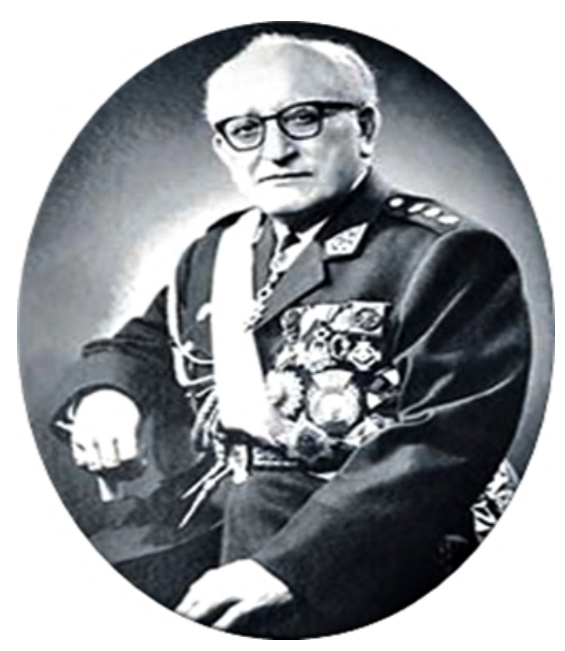

Figura 1: Retrato del general José del Carmen Marín Organizador del Centro de Altos Estudios Militares (CAEM).

Fuente: http://blog.derrama.org.pe/wpcontent/uploads/2015/03/164.jpg

Marín mencionaba la búsqueda del llamado "potencial nacional" para tener efectivamente un balance general de la situación del país ante un conflicto armado. Así justificaba "la inclusión de disciplinas no militares en la educación de los oficiales de alto rango" para poder aportar al bienestar general por encima de los fines netamente militares (Rodríguez, 1983).

Villanueva (1972) reconoce que, este cambio en el CAEM permitirá una transformación en los militares y que, además existió: 
Un deseo de una élite militar de cambiar la función profesional y tradicional de las instituciones castrenses, apartándolas de las tareas bélicas que son eventuales, para dedicarlas a funciones específicas de paz, de carácter permanente en beneficio de la colectividad. (p. 58)

Estos nuevos marcos conceptuales y visión que los militares manejarían los conectaron con las ideas de otros grupos políticos que se acercaban mucho a las inquietudes y demandas de ellos, aquí encontramos a la Democracia Cristiana (DC) y el Movimiento Social Progresista (MSP). La Democracia Cristiana surgió como partido en 1956; y en las elecciones presidenciales de 1962, postularon a Héctor Cornejo Chávez. En 1963, se aliaron a Acción Popular para apoyar la candidatura de Fernando Belaúnde, que ganaría dichas elecciones. Su postura, de manera general, incidía en la recuperación del hombre como centro de discusión frente a los embates de los imperialismos (norteamericano y soviético), así como de recusar el capitalismo y el comunismo.

El Movimiento Social Progresista, que surgió también en 1956, conglomeró a un grupo de intelectuales que decidieron plantear al país una serie de puntos para su discusión. En 1962, lanzaron como candidato presidencial a Alberto Ruiz Eldregde sin éxito alguno. Según el MSP, la solución para nuestro país consistía en lograr una revolución que devolviera a la colectividad el control de recursos naturales. Sostenían que el capitalismo era el causante del subdesarrollo y dependencia del país. Pero, a diferencia del socialismo estalinista, ellos propugnaban el camino "humanista" que permitía la expansión y desarrollo de las potencialidades del ser humano.

El Movimiento Social Progresista pedía, igualmente, una serie de reformas (Estado, empresa, agraria, crédito y educativa) destinadas a construir una sociedad auténticamente nacional y popular (Tuesta, 1998). Estas coincidencias notables con el pensamiento de los militares que iniciaron el proceso de 1968 llevaron después a invitar a los integrantes de estas agrupaciones como asesores y técnicos en los programas de reformas. Por ejemplo, Héctor Cornejo Chávez fue destacado asesor del general Velasco al igual que Alberto Ruiz Eldregde del MSP. Augusto Salazar Bondy fue uno de los principales gestores de la Ley General de Educación de 1972 (Kruijt, 1994).

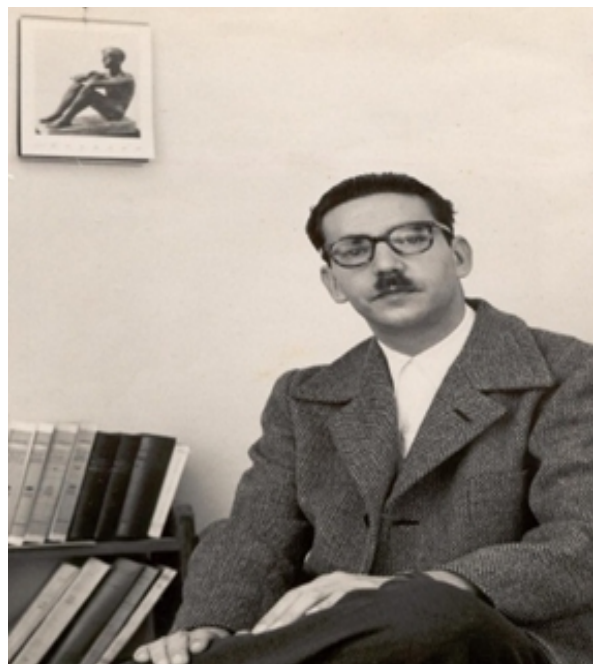

Figura 2: Augusto Salazar Bondy

Filósofo y Gestor de la Reforma Educativa del Gobierno de Velasco, integrante del Movimiento Social Progresista.

Fuente:https://gacetadeeducacion.files.wordpress.c om/2014/02/augusto-salazar-bondy.jpg

\section{El humanismo cristiano y el humanismo revolucionario: un breve acercamiento}

Al revisar las llamadas "Bases ideológicas de la revolución peruana", se presentaron algunas observaciones. Por ejemplo, que estas fueron publicadas recién en febrero de 1975 y aparecieron en el diario El Peruano. Esta publicación tardía hace pensar que hubo cierta improvisación en la construcción de las ideas del régimen, aunque podemos rastrear conceptos repetidos en discursos, entrevistas, artículos publicados o sostenidos por los integrantes del gobierno militar con anterioridad a la aparición de esas bases ideológicas.

Existe un énfasis al referirse al humanismo revolucionario, recogido desde tres tipos de inspiración: socialista, libertario y cristiano. En 
lo que respecta a la influencia del pensamiento socialista, se rescata: "una idea de propiedad social y promover la concepción del "Estado Participativo"; y aspirar a un ordenamiento en el cual los bienes socialmente generados beneficien a sus productores y a toda la sociedad"(Del Pilar Tello, 1983, p.355).

Asimismo, las "Bases ideológicas de la revolución peruana" sostienen que se busca llegar a "una sociedad solidaria, como derecho inviolable, la esencia libertad del ser humano" (Del Pilar Tello, 1983). Aquella idea fue recogida del pensamiento libertario. En cambio, de la experiencia cristiana, si bien se menciona argumentos semejantes a los anteriores expuestos, se resalta "la idea de la solidaridad, la justicia social y que la familia constituye el fundamento de la sociedad y es escuela del más rico humanismo" (Del Pilar Tello 1983, p.356).

Esta peculiar distinción ideológica colisionaba con las percepciones personales de los militares que participaban del proceso, siendo muchos de ellos opuestos a estar cerca de una posición progresista. La investigadora Lisa North intentó una clasificación ideológica de los generales del proceso al distinguir progresistas, centristas, derecha y extrema derecha. Según North (citada en Lowenthal y Meclintack, 1985) el balance se daba entre centristas y progresistas, debido a que los primeros asumían una posición tecnocrática que mediaba entre los extremos, como Fernández Maldonado (progresista) y José Graham (centrista), ambos importantes miembros del régimen velasquista.

La cercanía de los militares con las ideas de la doctrina social de la Iglesia era notoria, no solo por ser muchos de ellos, católicos; sino por las simpatías con las ideas que partieron de las encíclicas del Papa Juan XXIII (Mater et Magistra, y Pacem in Terris) y de Pablo VI (Populorum progressio).

La evolución que había tenido la Iglesia Católica estaba representada en los nuevos movimientos de sacerdotes motivados por las encíclicas papales; encontrándose una coincidencia con las ideas de los militares reformistas. La relación entre el Gobierno del general Velasco y la Iglesia fue cordial. Los militares reconocían la importancia de la Iglesia como institución y del cristianismo como credo popular; y en algunos casos, su reconocimiento como el bastión social que en palabras de Fernández (1973) era: "el parapeto más seguro contra las deformaciones del individualismo, el egoísmo y el endiosamiento materialista que nos trajera una sociedad occidental feudal asentada después en un capitalismo incipiente, intermediario $\mathrm{y}$ colonizado por el imperialismo" (p.41).

Este vínculo significó a un acercamiento con la nueva doctrina social de la Iglesia, llegándose incluso a consultar con dicha institución sobre medidas importantes como la ejecución de la reforma agraria y otros programas sociales.

Klaiber (1980) menciona este acercamiento y la consulta que realizaban a la Iglesia antes de iniciar la discusión de una ley de reforma. Esta relación era notable; aunque había una posición distante con los militares del proceso, el llamado Movimiento Sacerdotal ONIS mantuvo una política de crítica y observación con las medidas del proceso (Ramírez, 2014).

El Gobierno militar planteó seguir un humanismo revolucionario que consideraba al hombre como fin y no como medio, se postula "una realización plena de la persona humana, coincidiendo en la búsqueda de la libertad y la justicia como valores inseparables, indisolublemente ligados, y que deben estar presentes en el modelo societal que pensamos y en el que seguimos pensando para la nueva sociedad" (Del Pilar Tello, 1983, p.129). Esta idea fue sostenida por Fernández Maldonado y la tomamos en cuenta, pues fue uno de los gestores de las bases ideológicas y de los documentos principales (Plan Inca, Estatuto y el Manifiesto).

De la misma forma, el general José Graham, director del COAP (Comité de Asesoramiento de la Presidencia), en un discurso en la Conferencia Anual de Ejecutivos (CADE) 1971 titulado "El hombre: eje del sistema social de la Revolución Peruana", (1971) sostuvo que: 
La revolución se ha decidido por un humanismo que considere al hombre como eje del sistema social. Un humanismo que tenga la idea de justicia, como valor concreto de la vida en sociedad. Un humanismo cuya problemática del hombre en sí conlleve la problemática fundamental de la justicia y la libertad como valores inseparables y recíprocos. Este es el humanismo verdadero de la Revolución Peruana. (p.3)

La mención constante del hombre como centro de las acciones se refería a ubicarlo dentro de las preocupaciones, así mismo de liberarlo no solo de su carga individual, sino también de promover su participación en los programas de reformas que el Gobierno Militar dirigía. Dicho Humanismo debía centrarse hacia al desarrollo pleno, es decir, "un desarrollo humanista como doctrina y acción que se identifican plenamente con los pueblos del tercer mundo, para liberarlos de la miseria, de la dependencia, de la explotación; en pocas palabras para devolverle el bienestar y la plenitud de épocas vividas en el pasado" (Céspedes, 1973, p.114).

Estos cambios implicaban la transformación de todas las estructuras vigentes para generar una verdadera libertad. Delgado (1973), uno de los ideólogos más importantes y el gestor del Sistema Nacional para la Movilización Social (SINAMOS), menciona más sobre ese aspecto:

La libertad entendida por el Gobierno revolucionario es ilusoria en condiciones de desigualdad social, porque la libertad política real solo puede existir en condiciones de justicia, es decir, cuando se la ejerce en ausencia de relaciones de explotación económica. Más aún, para nosotros la libertad es una "dimensión esencial de la justicia”. (p.36)

Este plan de ejercer la liberación plena del hombre estaba precisamente en la orientación de las reformas, sin embargo, uno de los pesos lo constituiría la educación, porque ella gestaría la formación de "un hombre nuevo" que pueda notar los avances de la Revolución. Este humanismo revolucionario empalmaba muy bien con las perspectivas del hombre que tenía la Democracia Cristiana, donde señalaban que "el hombre mantenía un destino de superación y que fue el cristianismo el que aportó de golpe, entre aquellos tanteos, una visión decisiva de la persona, de su valor sustantivo, de su entidad individual, de su propio e intransferible valor, de su intrínseca dignidad" (Cornejo, 1975, p.9).

Aquella dignidad permitía que "el hombre siempre buscara superar sus metas y que por lo tanto esté llamado a una vida y un destino superior al tiempo y que la persona trascienda todas las sociedades temporales y les es superior" (Cornejo, 1975, p.13). Por supuesto que este valor estaba siempre ligado al desarrollo del hombre en la sociedad y también el de incentivar la solidaridad.

Las coincidencias entre la Democracia Cristiana y el Gobierno Militar eran importantes. Según Cornejo (1975), los objetivos comunes sobre el papel del hombre en la revolución y en rescatar su vocación solidaria eran importantes; sin embargo, reconocía que el humanismo revolucionario de los militares no se acercaba al ámbito espiritual, sino que partían de un punto materialista y eso impedía conocer al hombre en toda su plenitud. Además, en el ámbito político se pretendía apartar a la clase media del proceso, cuando lo correcto era incentivar su participación para la realización plena del humanismo que los militares sostenían.

Finalmente, la influencia de la doctrina social de la Iglesia Católica, como ya habíamos mencionado, discutió el planteamiento de una nueva sociedad bajo los postulados del socialismo, que no era tan discriminatorio y explotador como el capitalismo; ya que "el capitalismo se basa en el lucro, mientras que el 
socialismo permite la intervención del Estado para llevar a cabo las reformas necesarias en bien de la sociedad y no de un limitado grupo que trata de mantener sus intereses de clase" (Ramírez, 2014, p.80-81).

Esta coincidencia fue tomada para fundamentar el valor de la revolución que los militares organizaban y se justificaba también en los valores cristianos. Por ello, Delgado (1974) concluía que:

El humanismo revolucionario supone un interés fundamental no en "el hombre abstracto", sino, por el contrario, en los hombres reales y concretos que forman una sociedad. Esta concepción del humanismo está en la raíz y en la tradición de todos los ideales libertarios y de todos los credos éticos de las grandes corrientes religiosas de la humanidad. Está, por lo tanto, en el sustrato más hondo del mensaje moral del cristianismo y también de la formulación primera y fundamental del planteamiento socialista. (p.38)

Estas similitudes conceptuales llevarían a la búsqueda de "un hombre nuevo, solidario, liberado de la explotación y de la alienación" (Aguirre, 1974, p.45). Sin embargo, el resultado final distó mucho de llegar a la meta que esperaban.

\section{Sobre la democracia social de participación plena}

En las bases ideológicas, uno de los principios que eran defendidos por los militares del proceso fue la idea de la democracia social de participación plena, un concepto que reemplazaba en gran parte al del socialismo, debido al rechazo en su total acepción entre los militares y parte de la población. José Graham menciona precisamente esta característica, debido a que según él, dicha palabra se encontraba "satanizada" en el medio, por lo que se cambió en los discursos por la palabra "sociedad de participación" (Del Pilar Tello, 1983).

Los elementos esenciales de este concepto fueron "la participación popular, un sistema económico pluralista basado en la propiedad social y un sistema social sustentado en diversos valores morales (justicia, libertad, trabajo, solidaridad, etc.)" (Del Pilar Tello, 1983, p.357).

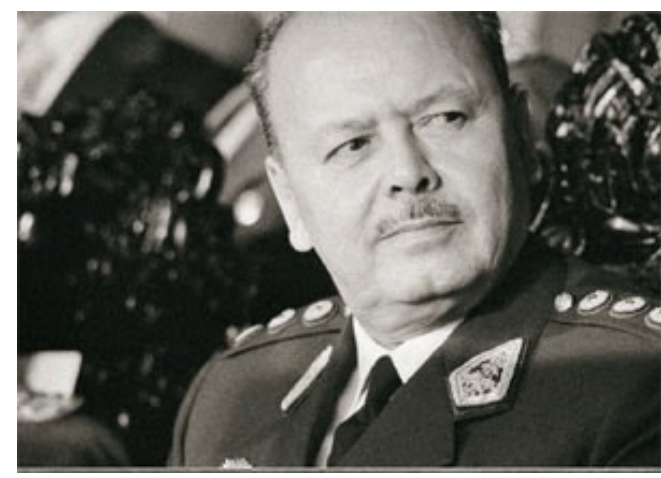

Figura 3: Juan Velasco Alvarado (1910-1977)

Director y artífice del llamado "Gobierno

Revolucionario de la Fuerza Armada".

Fuente:http://todosobrelahistoriadelperu.blogspot.c om/2013/10/golpe-de-estado-del-general-juan.html

La idea de fomentar este concepto implicaba diferenciarse de los modelos existentes y de generar, efectivamente, una tercera vía: un camino propio. Las leyes que impulsaron esta idea fueron las de Propiedad Social y Comunidad Industrial, el objetivo era delegar el control y la autogestión a los trabajadores como meta final. Sin embargo, al momento de iniciarse este proceso, el gobierno militar tuvo que reconocer cuatro tipos de propiedad: "la privada, la privada reformada, la social (en colaboración entre los obreros y la gerencia) y la estatal" (Klaiber, 1980, p.212).

El problema de la participación no era idea original de los militares del proceso peruano, existían experiencias como las proporcionadas en países como Yugoslavia y Argelia, en base a la autogestión de las empresas por los trabajadores. Además, había cercanías con el planteamiento de la Democracia Cristiana sobre la Sociedad Comunitaria. En esta idea, el Estado debía cumplir un rol importante para independizar los medios de producción del control capitalista y de la oligarquía.

Asimismo, planteaba la fusión del poder ejecutivo para crear el poder gubernativo que pueda tener injerencia en el desarrollo 
económico, "con el fin de reemplazar el lucro por la satisfacción de necesidades reales como motor de la economía" (Cornejo, 1975, p. 216). Finalmente, la Democracia Cristiana reconocería tres tipos de propiedades: "la privada individual, la comunitaria y la estatal" (Cornejo, 1975, p. 220). Sus discrepancias con el modelo de propiedad social eran su excesivo intervencionismo estatal y la no inclusión de otros sectores participativos como las cooperativas, comunidades campesinas, entre otras.

Siendo así las similitudes, esta democracia defendida por el gobierno militar tenía que distanciarse de la democracia representativa y optar por una democracia social participativa, es decir, directa. "Con la intervención de la población, en pocas palabras, se habla de una transferencia de poder" (Franco, 1975). Esta idea interfirió con la formación de un partido de la revolución, en cambio, se impulsará un organismo que se encargaría de fomentar la participación de la población, esta institución seria el Sistema Nacional para la Movilización Social (SINAMOS), creado en 1971.

El impulso de la autogestión fue determinante para identificar al proceso peruano, la organización de la administración de las empresas, el fomento del surgimiento de sindicatos estuvo en constante ebullición bajo el fin de la participación popular en las decisiones. Neira (2009) menciona que la aparición creciente de sindicatos y ligas agrarias durante el velasquismo formó una sociedad civil y no una clientela. Hecho importante para él, que fue determinante en los años posteriores al final del Gobierno de Velasco.

La preocupación extendida sobre la participación, necesaria para llevar a cabo el concepto de la democracia social de participación plena, fue de generar por etapas la concientización y desarrollo de la misma, desde los sectores más desfavorecidos y con proyección hacia la cercanía al poder político. Carlos Franco señalaba que la participación popular era un fin de la revolución peruana y también un medio porque básicamente "la construcción de una nueva sociedad peruana precisa de la priorización de instituciones económicas, representativas y participativas a través de las cuales progresivamente todos los peruanos intervengan responsablemente en el desarrollo nacional" (Franco, 1975, p. 80).

Entre estas instituciones se encontraban las Cooperativas Agrarias de Producción Social (CAPS), las Sociedades Agrícolas de Interés Social (SAIS) y las variadas comunidades industriales.

Las complicaciones de la aplicación de las medidas, basadas en la participación popular plena, fueron el encontrarse poca capacitación técnica, reducida coordinación con los sectores representantes del Estado, así como la oposición de los partidos políticos, los sindicatos y parte de la sociedad civil (Franco, 1975). El general Arturo Valdés mencionaba parte de estos errores que no fueron atendidos en su momento y recordaba que "lo que deberíamos haber hecho es fomentarlo en el pueblo, pero no se logró hacerlo, porque se chocaba con problemas inclusive dentro del propio gobierno. Fomentar e ir estimulando a ese pueblo para que se fuera desarrollando hasta que comenzara a reclamar lo suyo" (Béjar y Franco, 1980, p. 35).

Ese reclamo seria asumir los ideales del proceso y llevarlos a la ejecución de los mismos.

Por ello, el general Velasco decía que una democracia social de participación plena solo puede existir en un pueblo integralmente preparado para regir sus destinos en base a la intervención consciente y libre de sus miembros en todas las esferas de la vida social. El logro de este objetivo fundamental solo puede alcanzarse a través de un largo proceso de formación de una alta conciencia ciudadana (Ministerio de Educación, 1974).

La reforma de la educación contribuía, en ese sentido, plenamente con fomentar esa conciencia ciudadana que el general Velasco pedía. Sin embargo, los resultados fueron a la larga desalentadores por la fuerte oposición, 
que hacía ver el ámbito ideológico muy lejos de la realidad y la mentalidad del ciudadano.

Finalmente, en los años finales del régimen militar y la salida del general Velasco del poder, la huelga general de la Guardia Civil y los continuos paros generales impulsados por los sindicatos de trabajadores hicieron diluir el empeño de generar la participación popular, que era desbordada por las situaciones.

El "socialismo con chullo", un camino propio para el proceso peruano, se diluía así en otra fase que rechazó y detuvo las reformas impulsadas desde 1968.

\section{CONCLUSIONES}

Después de recorrer brevemente algunos de los argumentos principales que contenían las "bases ideológicas de la Revolución Peruana", observamos que el grupo de militares que liderarían los procesos iniciados desde 1968 compartían muchas similitudes conceptuales con los diferentes movimientos políticos internos y externos. El humanismo revolucionario, impulsado en el proceso, fue pensado como una totalidad que debía abarcar las diferentes estructuras políticas, económicas y sociales. Eso permitió empalmar objetivos con otras instituciones como la Iglesia Católica, la Democracia Cristiana y el Movimiento Social Progresista, con la meta en el caso del primero, de no solo realizar un reconocimiento a una tradición religiosa presente, sino también a la identificación de los militares con un credo cristiano.

El afán de los militares por diferenciarse de los modelos antagónicos vigentes (capitalismocomunismo), los llevó a plantear la democracia social de participación plena, como posición propia y nacional, cuyo proyecto debía ser original y que proyectara una imagen del Perú al edificar su propio camino, su tercera vía al desarrollo y la independencia.

Finalmente, concluimos que el sentido ideológico y el esmero, puestos por técnicos, intelectuales y militares, durante el proceso, fueron muy ambiciosos para una sociedad que todavía no entendía el peso de los cambios que este grupo de gestores pensaba para el país.

\section{REFERENCIAS BIBLIOGRÁFICAS}

Aguirre, H. (1974). El proceso peruano. Cómo, por qué, hacia dónde. México: Ediciones El Caballito.

Béjar, H. y Franco, C. (1980). Autogestión en el Perú 1968-1979. Lima: Centro de Información y Desarrollo internacional de Autogestión (CDIAG).

Céspedes, T. (1973). La revolución peruana. Lima: Nueva Constitución S.A.

Cornejo, H. (1975). Socialcristianismo y revolución peruana. Lima: Centro andino de capacitación y estudios.

Delgado, C. (1974). Testimonio de lucha. Lima: Editorial PEISA.

Del Pilar Tello, M. (1983). ¿Golpe o Revolución? Hablan los generales del 68. Lima: Ediciones Saqsa, 2 Vols.

Franco, C. (1975). La revolución participativa. Lima: Mosca Azul editores.

Fernández, J. (1973). Fuerza Armada, cristianismo y revolución. Participación, (2), 4-13.

Graham, J. (1971). El hombre: eje del sistema social de la Revolución Peruana. Lima: Empresa Editora Diario El Peruano.

Klaiber, J. (1980). Religión y revolución en el Perú 1824-1976. Lima: Universidad del Pacifico.

Kruijt, D. (1991). La revolución por decreto: Perú durante el gobierno militar. Lima: Facultad latinoamericana de Ciencias Sociales, Mosca Azul Editores.

Lowenthal, A. y Mcclintock, C. (1985). El gobierno militar, una experiencia peruana, 1968-1980. Lima: Instituto de Estudios Peruanos.

MINISTERIO DE EDUCACIÓN. (1974). El proceso peruano. Lima: Ministerio de Educación, Instituto Nacional de Investigación y desarrollo de la educación "Augusto Salazar Bondy".

Neira, H. (2009). Hacia la tercera mitad. Perú XVI-XX. Ensayos de relectura herética. Lima: Universidad Inca Garcilaso de la Vega, 2 Vols. 
Ni capitalista, ni comunista: apuntes sobre las bases ideológicas del Gobierno Revolucionario de la Fuerza Armada del Perú (1968-1975)

Enero - junio 2019

Ramírez, J. (2014). Movimiento Sacerdotal ONIS. La Iglesia en el Perú ante las demandas de justicia social 19681975. Lima: Seminario de Historia Rural Andina, Universidad Nacional Mayor de San Marcos.

Rodríguez, J. (1983). Los militares y el poder. Un ensayo sobre la doctrina militar en el Perú 1948-1968. Lima: Mosca Azul Editores.
Tuesta, F. (1998). El movimiento social progresista [Blog]. Recuperado de http://blog.pucp.edu.pe/blog/fernand otuesta/1998/08/26el-movimientosocial-progresista/

Villanueva, V. (1972). El CAEM y la Revolución de la Fuerza Armada. Lima: Instituto de Estudios Peruanos, Campodónico Editores. 